P-ISSN: 0216_4396 Jurnal Tapis: Jurnal Teropong Aspirasi Politik Islam 15

(6) (2019) 115-141

e-ISSN: 2655-6057 https:// http://ejournal.radenintan.ac.id/index.php/TAPIs/index

\title{
PARTAI KEADILAN SEJAHTERA (PKS) DALAM SOROTAN MEDIA DI INDONESIA
}

\author{
Mohamad Ramadan Habibi \\ Program Studi Ekonomi Syariah, IAI Agus Salim Metro Lampung \\ Metro Lampung \\ Ramadhan.habibi@gmail.com
}

Diterima: 23/03/2019 Disetujui: 15/06/2019 Dipublikasikan: 23/06/2019

\begin{abstract}
The presence of the Partai Keadilan Sejahtera has become a new phenomenon. His appearance that emphasizes morals and politeness makes this Islam-based party overwhelmingly welcomed with a significant increase in votes. This party often gets the spotlight from the mass media and observers. This article presents a number of media reports about PKS, and the extent of its accuracy. Does it have implications for elections.
\end{abstract}

Abstrak: Kehadiran Partai Keadilan Sejahtera dikancah perpolitikkan Indonesia menjadi fenomena baru. Penampilannya yang mengedepankan moral dan kesantunan menjadikan partai berasaskan Islam ini mendapat sambutan yang luar biasa dengan peningkatan suara yang signifikan. Partai ini kerap mendapat sorotan dari media massa dan pengamat. Sebagaimana kita ketahui bahwa salah satu fungsi media masa yakni sebagai pengawasan sosial (sosial control) terhadap perilaku publik dan penguasa.

\section{Kata Kunci: Akurat, Pemilu, PKS, Media}

\section{PENDAHULUAN}

Terjangan krisis ekonomi yang melanda negara-negara Asia termasuk Indonesia pada awal jun 1997 kemudian diikuti kerusuhan yang terjadi dikota-kota besar seperti Jakarta, Medan, Solo, Banyuwangi, Yogyakarta, Padang dan Surabaya pada awal $1998^{1}$

${ }^{1}$ Lihat " Rusuh di Medan, Padang, Yogya” Gatra 16 Mei, 1998, p.24-33. Lihat juga "Huru-Hara Jakarta," Gatra 23 Mei, 1998, 


\section{Habibi : Partai Keadilan Sejahtera (PKS) Dalam Sorotan.........}

mengakibatkan rapuhnya kekuasaan otoriter Presiden Seoharto yang telah memimpin Indonesia sejak tahun 1966. Puncaknya ditandai oleh turunnya Soeharto dari jabatan Presiden pada tanggal 21 mei 1998 sehingga berakhirlah rejim Orde Baru. Sejak saat itu Indonesia mengalami perubahan politik yang sangat drastis dengan terbukanya jalan seluas-luasnya bagi perubahan ditingkat institusi Negara.

Bacharuddin Jusuf Habibi adalah orang pertama yang memegang kekuasaan di era reformasi ini. Habibi mengawali reformasi politiknya dengan mengadakan pemilu multi parti yang demokratis pada tanggal 7 juni 1999, membebaskan tahanan politik, desentralisasi kekuatan politik (decentralization political power), mengizinkan partai politik baru untuk ikut berpartisipasi dalam pemilu, dan kebebasan pers (liberalized the press laws). ${ }^{2}$ Perubahan yang signifikan lainnya adalah pencabutan TAP MPR RI No. II / MPR / 1983 tentang pencabutan pancasila sebagai asas tunggal Negara dalam Sidang Umum MPR RI tahun 1999 dari tanggal 14-21 oktober 1999. Inilah untuk pertama kalinya dalam sejarah konstitusi Indonesia dilakukan amandemen pertama terhadap Undang-Undang Dasar 1945. Perkembangan ini membawa Indonesia kepada Negara yang paling demokratis diantara negara-negara di asia tenggara, seperti yang dilaporkan oleh Freedom House and Polity $I V^{3}$

Respon yang paling nampak di era reformasi ini adalah tumbuhnya partai-partai politik baru bagai cendawan di musim hujan, termasuk lahirnya partai-partai politik yang berasaskan Islam. Antara bulan mei dan oktober 1998 Indonesia menyaksikan lahirnya 181 partai politik meskipun yang mendaftar ke Departemen Kehakiman

\footnotetext{
${ }^{2}$ Marco Bunte and Andreas Ufen, "Democratization in Post-Suharto Indonesia, " Routledge Contemporary Southeast Asia Series, p. 3

3 "Freedomhouse, 'Combined Average Ratings: Independent Countries in 2009,' [accessed September 26, 2009], <http://www.freedomhouse.org>; 'Polity IV Country Report 2007, 'Indonesia,' [accessed September 26, 2009], <http://www.systemicpeace.org/polity/Indonesia2007.pdf>.," t.t.
} 


\section{Habibi : Partai Keadilan Sejahtera (PKS) Dalam Sorotan.........}

hanya berjumlah $141 .^{4}$ Empat puluh dua diantaranya adalah partai yang dapat dikategorikan sebagai partai Islam kerana menggunakan simbol dan ideologi Islam, namun selanjutnya hanya 20 patrai saja yang lulus hasil verifikasi Departemen Kehakiman dan boleh berpartisipasi dalam pemilu 7 juni $1999 .{ }^{5}$ Disamping itu perubahan yang dilakukan oleh Habibi dengan mencabut Peraturan Departemen Penerangan (Permenpen) No.1 tahun 1984 tentang Surat Izin Usaha Penerbitan Pers (SIUPP) pada tanggal 5 juni 1998 membawa angin baru bagi kebebasan pers dan kesannya langsung dirasakan dengan gaya pemberitaan di media massa yang mulai berani memantau dan mengkritik performance pemerintah dan partai politik dengan bahasa yang lugas dan keras, termasuk pemberitaan tentang dugaan korupsi mantan presiden Soeharto.

Kebebasan ini menghantarkan bangsa Indonesia pada situasi fenomenal yang tidak terjadi dimasa Orde Baru, dimana ketika itu partisipasi masyarakat terhadap politik sangat dibatasi oleh pengawasan yang ketat dengan cara penyederhanaan partai politik. Alasan adalah agar lebih mempermudah pemilu tanpa menghilangkan identitas partai masing-masing. Pengelompokkan ini mencakup tiga kelompok, yaitu Golongan Nasional, Golongan Spritual, dan Golongan Karya (Golkar). Pengelompokan dalam tiga golongan ini baru terjadi pada tahun 1973. Partai-partai Islam bergabung menjadi Partai Persatuan Pembangunan (gabungan NU, PSII, PMI dan Perti), sedangkan PNI, PARKINDO, Partai Katolik, Partai Murba dan Partai Ikatan Pendukung Kemerdekaan Indonesia (IPKI) bergabung menjadi Partai Demokrasi Indonesia. Jadi, dapat disimpulkan bahwa pada masa Orde Baru hanya ada tiga parti politik, yaitu PPP, PDI, dan Golkar. ${ }^{6}$

4 “Partai-Partai Politik Indonesia: Ideologi, Strategi, dan Program," Litbang Kompas 1999, p. xi-xii.," .

${ }^{5}$ Arsekal Salim, Partai Islam dan Relasi Agama-Negara, "Pusat Penelitian IAIN Jakarta 1999, p. 7-12 (Jakarta: Pusat Penelitian IAIN Jakarta 1999,).

${ }^{6}$ Miriam Budhiardho, Miriam Budhiardho, "Demokrasi," Jakarta: Gramedia, p.202-209. (Jakarta: Gramedia,). 


\section{Habibi : Partai Keadilan Sejahtera (PKS) Dalam Sorotan.........}

Selain itu pengawasan media pun sungguh ketat dibawah Departemen Penerangan. Media ketika itu cenderung dijadikan alat propaganda oleh rejim otoriter untuk menstabilkan kekuasaannya. Sehingga media dalam bentuk apapun selalu mengalami keadaan yang dilematis. Khususnya media yang berbentuk hard news, soft news, danfeature sangat rentan jika berbicara apapun yang negatif dan mengkritik Presiden Soeharto, pemerintahan, partai Golkar. Media yang bersangkutan akan terancam dicabut surat izin penerbitannya atau yang biasa disingkat SIUPP (Surat Izin Usaha Penerbitan Pers). Kasus yang pernah terjadi adalah dicabutnya SIUPP majalah Tempo pada tahun 1982 dikarenakan meliput kampanye partai Golkar yang berakhir dengan huru-hara. ${ }^{7}$ Majalah yang mendapatkan nasib yang sama adalah Majalah Detik dan Editor karena terlalu lantang dan lugas dalam pemberitaannya.

Bagi para politisi, era reformasi adalah euforia kebebasan untuk menyuarakan cita-cita politiknya. Dan bagi media, iklim yang kondusif ini dimanfaatkan sebagai era keterbukaan dan transparansi disamping sebagai ladang bisnis yang menjanjikan keuntungan. Dengan kata lain, kondisi ini dimanfaatkan oleh politisi untuk mengekspresikan ide politiknya dengan cara mengkampanyekan program-program partai agar mendapatkan pendukung. Disisi lain para wartawan media akan menggunakan momentum kebebasan ini untuk memberitakan fakta yang terjadi, seperti kasus korupsi ditingkat pejabat pemerintah atau kritik terbuka terhadap sistem birokrasi Indonesia yang lemah. Seperti diungkapkan oleh M. Jasin Naib Komisi Pemberantasan Korupsi KPK (Anti-Corruption Commission); Banyak kasus korupsi yang melibatkan Pejabat Negara dan Pemerintah tengah ditangani oleh KPK sehingga mereka tidak senang dengan keberadaan $\mathrm{KPK}^{8}{ }^{8}$ dan tentunya media akan diuntungkan oleh berita-berita yang bombastis seperti ini dan akan menyedot perhatian

7 "Sejarah Majalah Tempo, Konflik dan Pembredelan [accessed april 1, 2011], <http://sejarah.kompasiana.com>," 2011.

${ }^{8}$ Siti Aminah, “'Politik Media, Demokrasi dan Media Politik,' [accessed January 3, 2012], <http://journal.unair.ac.id>.," 2012. 
publik. Selain itu media juga dapat dijadikan sarana kampanye bagi partai politik.

Hubungan antara partai politik dan media dapat dikatakan sebagai hubungan saling menguntungkan. Apalagi setiap kali mendekati datangnya pemilu, maka peran media amat strategis sekali dalam mengangkat citra sebuah partai. Begitupula sebaliknya, media dapat menjatuhkan citra sebuah partai tertentu dengan mengungkapkan dosa-dosa dan skandal politiknya, atau menyebarkan fitnah dan berita bohong berupa laporan yang datanya tidak akurat dan terkesan dibuat-buat. Pada sisi lain media juga dapat dijadikan sebagai senjata bagi pihak tertentu untuk menyerang musuh politiknya. Singkatnya, media juga menjalankan peran politik, media dapat menjadi alat melawan bahkan menggulingkan pemerintahan represif bahkan diktator. Media memiliki keleluasaan gerak politiknya, tidak hanya menyuarakan dan tunduk pada mekanisme pasar sesuai dengan model neoliberal ekonomi. Tapi media juga dapat berperan mendukung konsolidasi demokrasi dan hal ini merupakan otonomi politik media. $^{9}$

Gambaran diatas akan tampak jelas jika diungkapkan contoh kasusnya satu persatu. Akan tetapi dalam kajian ini penulis hanya memfokuskan kepada isu-isu yang diberitakan oleh media tentang Partai Keadilan Sejahtera (PKS) karena penulis merasa PKS merupakan partai yang cukup mempunyai isu yang menarik selain itu Penulis memilih partai ini sebagai sample kajian, sebab pertama; PKS merupakan partai yang berbasis Islam, salah satu partai yang lahir di era reformasi dan sama sekali tidak mempunyai hubungan apapun dengan rejim Orde Baru. ${ }^{10}$ Partai ini bukan terlahir dari rahim organisasi besar seperti Nahdlatul Ulama (NU), Muhammadiyah, atau Pesatuan Islam (Persis). Kedua; Parti ini mampu meraup suara umat Islam dengan jumlah yang signifikan bagi sebuah partai pendatang

\footnotetext{
${ }^{9}$ Aminah.

${ }^{10}$ Zachary Abuza, Political Islam and Violence in Indonesia (Routledge Taylor \& Francis Group, p. 22,).
} 


\section{Habibi : Partai Keadilan Sejahtera (PKS) Dalam Sorotan.........}

baru. Pada pemilu 1999 mendapat jumlah suara 1,4\%, 2004 meningkat 7,3\% dan 2009 naik menjadi 7,8\%. Ketiga; Sejak kemunculannya hingga sekarang, PKS membangun reputasinya dengan berkomitmen memerangi korupsi. ${ }^{11}$ Hal ini dibuktikan oleh ahli parlemen dan kader PKS yang menduduki jabatan publik tidak pernah terlibat kasus korupsi. Dengan demikian hadirnya partai ini direspon masyarakat sebagai harapan baru bagi perubahan pola perpolitikan Indonesia yang selama ini ternodai oleh korupsi dan tindakan asusial yang dilakukan oleh elit politik. Keempat; Disamping membawa harapan baru, partai ini dinilai oleh sebahagian kalangan membawa ancaman berupa agenda tersembunyi iaitu mendirikan Negara Islam. ${ }^{12}$ Diantara beberapa pengamat mengatakan bahwa PKS memiliki double agenda iaitu: Public Agenda fokus kepada pemberantasan korupsi, kerja yang professional, dan good governance. Sedangkan Private Agenda fokus kepada pemurnian ajaran Islam dan menegakkan shari'ah. ${ }^{13}$ Kelima; Kebanyakan media di Indonesia telah dikuasai oleh kepentingan partai Sekular, ${ }^{14}$ mereka berhasil menggunakan media sebagai alat politik untuk memobilisasi dukugan publik dan untuk memenangkan pemilu. Kemenangan partai nasionalis ${ }^{15}$ pada pemilu tahun 2009 mendapatkan hasil $49 \%$ salah satunya ditopang oleh media massa seperti iklan di televisi yang menjadi kekuatan baru dan lebih masif dalam memainkan peranannya menyebarkan informasi politik kepada publik.

${ }^{11}$ William Liddle William Liddle, "'Politics, Islam and Public Opinion', Journal of Democracy, Vol. 15, NO.1, January 2004.,"

${ }^{12}$ Saiful Mujani William Liddle, "Muslim Indonesia's Secular Democracy,” Asian Survey Vol. XLIX. NO.4. July/August 2009, p. 590. Zachary Abuza, op.cit, p. 25," 2009.

13 "Zachary Abuza, op.cit, p. 25,".

${ }^{14}$ Saiful Mujani and William Liddle, Ibid, p. 589,

15 "Termasuk parti secular adalah Partai Golkar, Partai Demokrasi Indonesia Perjuangan (PDIP) dan Partai Demokrat (PD).," t.t. 


\section{Habibi : Partai Keadilan Sejahtera (PKS) Dalam Sorotan.........}

Data survei menunjukkan bahwa masyarakat Indonesia paling banyak mendapatkan informasi politik melalui televisi $(87 \%){ }^{16}$

Berdasarkan alasan diatas sehingga kemunculan PKS di kancah perpolitikkan Indonesia menjadi daya tarik tersendiri bagi media massa dan pengamat politik dari dalam dan luar negri. Hal ini disebabkan oleh perjalanan politik PKS yang meningkat dari hari ke hari. Disaat suara parti Islam lain mengalami penurunan suara pada pilihan raya 1999, 2004 dan 2009, PKS terus mengalami peningkatan suara.pada tahun 1999 memperoleh $1,51 \%$ pada tahun 2004 memperoleh $8,18 \%$ dan pada tahun ${ }^{17}$ Pada sisi lain, PKS dinilai sangat solid dan tidak mengalami konflik perpecahan didalam tubuh parti, sementara itu parti-parti Islam lainnya telah banyak mengalami perpecahan akibat konflik internal. Ini dialami oleh Partai Persatuan Pembangunan PPP yang terpecah kemudian muncul Partai Bintang Reformasi PBR, begitu pula dengan Partai Amanat Nasional PAN yang merupakan basis Muhammadiyah mengalami perpecahan dan muncul Partai Matahari Bangsa PMB, begitu pula dialami oleh Partai Kebangkitan Bangsa PKB dengan munculnya Partai Kebangkitan Nasional Ulama PKNU. Pada kondisi lain PKS sangat konsisten dalam memerangi korupsi, sejak dideklarasikan hingga sekarang tidak ada satupun kader PKS di Parlemen yang terseret kasus korupsi, justeru para kader PKS di parlemen mengembalikan uang suap dan dibagikannya kepada masyarakat. ${ }^{18}$ Sedangkan beberapa orang kader dari partai Islam lainnya yang menduduki jabatan publik terjerat

\footnotetext{
16 "Tele-Politics, iklan dan prilaku pemilih, [accessed january 12, 2012], $<$ "http://burhan15.multiply.com>.," t.t.

17 "Jawa Timur: Tembok Pembatas Mulai Terbelah", Kompas June 22, 2009, p. 8.,"

18 "Nasir Jamil dan Andi Salahuddin adalah anggota Fraksi PKS di Provinsi Nangroe Aceh Darussalam NAD telah mengembalikan wang intensif bulanan anggota Parlimen NAD dari bulan july-Desember 2005 sebanyak Rp 50.996.000, kemudian wang itu dibagikan kepada mangsa gempa bumi dan tsunami di Aceh. Lihat: Hartono, 'FPKS mengembalikan uang intensif bulanan ke masyarakat,' [accessed september 6, 2007], <http: www.fpk-dpr.or.id>.,"
} 


\section{Habibi : Partai Keadilan Sejahtera (PKS) Dalam Sorotan.........}

korupsi. ${ }^{19}$ Inilah fenomena PKS sehingga kehadirannya sangat diperhitungkan oleh lawan politiknya yang memiliki agenda yang berlawanan dengannya.

Paparan diatas menjadi menarik, kerana politik moral dan kesantunan kader yang selama ini ditunjukan oleh PKS bukanlah menjadi headline di media-media, meskipun demikian ada sebahagian yang diberitakan oleh media. Memberitakan kebaikan PKS dan segala prestasinya tidak menarik buat wartawan media, karena secara otomatis akan menjadi free campaign bagi mereka. Yang akan menguntungkan dan dicari oleh para wartawan adalah berita keburukan PKS meski fakta dan data yang diberitakan diragukan kebenarannya. Berita seperti ini akan menjadi berita heboh dan akan dicari oleh orang dan dengan sendirinya menaikkan oplah jualan media. Pernyataan diatas sangat beralasan, sebab selama ini PKS berpolitik dengan menjual isu partai yang bersih dari korupsi, justru jargon itu mengundang kecenderungan masyarakat untuk menyimak komitmen tersebut. Publik akan lebih heboh jika mendengar berita salah seorang kader PKS yang terjerat korupsi dari pada berita tentang penolakkan menggunakan fasilitas negara yang dilakukan oleh kader PKS seperti yang dilakukan oleh DR Hidayat Nur Wahid sebagai ketua Majlis Permusyawaratan Rakyat MPR RI priode 2004-2009 yang menolak mobil Volvo senilai Rp. 1 miliar dan penginapan di hotel dengan harga Rp. 1,5 juta permalam. ${ }^{20}$

19 "Kes rasuah pernah membabitkan parti Islam seperti PKB, lihat: “ Khofifah penuhi panggilan KPK terkait dana DKP', [accessed january 7, 2008], <http: www.antara.co.id>, Kes rasuah lainnya melibatkan PPP iaitu Mufrodi Muchsin ketua Dewan Pimpinan Wilayah DPW PPP Banten, dan merupakan Timbalan Dewan Perwakilan Rakyat Daerah Banten DPRD Banten, [accessed july 19, 2007], < http: www.bantenlink.com>. Kes lain yang membabitkan parti Islam adalah anggota parlimen dari PBB Tenggku Zubier Idris dan PAN Tjut Ali Umar iaitu Kes dugaan rasuah dana Anggaran Pendapatan Belanja Daerah APBD kota Banda Acehtahun 2002 senilai Rp 570.000.000." [accessed December 27, 2007]. <http: www.kompas.com>.

20 "Hidayat Nurwahid Manolak Fasilitas Mobil Volvo, [accessed on october 10, 2004] <http://berita.liputan6.com>.," 
Habibi : Partai Keadilan Sejahtera (PKS) Dalam Sorotan.........

\section{METODE PENELITIAN}

Berdasarkan permasalahan kajian diatas, artikel ini mencoba menganalisis segala data yang diperoleh dari sumber-sumber primary seperti liputan TV, majalah dan juga surat kabar yang berkaitan dengan berita PKS. Kemudian data dari berbagai media massa itu penulis cek kesahihannya dengan data yang penulis perolehi dari pihak PKS seperti pernyataan Petinggi PKS, web resmi PKS, dan buku-buku yang diterbitkan oleh PKS. Analisis ini disusun menjadi tiga bahagian. Pertama Pengenalan PKS. Kedua menyelidiki pemberitaan media berkisar isu-isu PKS dimulai dari periode 19992004, kemudian periode 2004-2009 dan yang terakhir tahun 2009 hingga 2011. Dalam kajian ini penulis tidak memuat semua berita media tentang PKS, penulis hanya menampilkan beberapa isu yang menyedot perhatian media dan publik. Kemudian penulis mencoba menganalisis keakuratan beritanya dengan merujuk kepada pernyataan dan sikap PKS. Bahagian ini pula berusaha menganalisis pengaruh pemberitaan di media dengan perolehan suara PKS pada pemilu 2004 dan 2009. Bahagian ketiga menganalisis stategi PKS dalam menanggapi isu akhir-akhir ini terutama pada tahun 2011.

\section{HASIL dan PEMBAHASAN}

\section{A. Pendiri Partai Keadilan Sejahtera}

Setelah gerakan reformasi berhasil meruntuhkan rezim Orde Baru pada 21 mei 1998 ditandai dengan turunnya Presiden Soeharto yang telah berkuasa selama 32 tahun, mulailah masyarakat menyadari adanya kekuatan besar yang terorganisir dengan rapi dan selama ini tidak tampil ke publik. Hal ini dibuktikan saat mereka keluar untuk mendeklarasikan Partai Keadilan pada 9 agustus 1998 yang dihadiri oleh sekitar 50.000 orang di halaman Masjid al-Azhar Jakarta Selatan $^{21}$. Ribuan masa tersebut adalah sebuah masyarakat baru, yang hlm. 215 .

${ }^{21}$ Ali Said Damanik, Fenomena Partai Keadilan (Jakarta: Teraju, 2002), 


\section{Habibi : Partai Keadilan Sejahtera (PKS) Dalam Sorotan.........}

telah dibangun selama bertahun-tahun dalam gerakan tarbiyah. Sehingga dalam masa lima bulan sejak berdirinya pada bulan agustus hingga desember 1998, Partai Keadilan telah memiliki 25 perwakilan Dewan Pimpinan Daerah (DPW) di 25 provinsi, 200 Dewan Pimpinan Daerah (DPD) tingkat kota dan kabupaten, dan 400 Dewan Pimpina Cabang (DPC) di tingkat Kecamatan (sub-district). ${ }^{22}$

Pilihan Raya 1999 adalah pemilu pertama yang diikuti oleh Partai Keadilan dan memperoleh urutan ketujuh dengan suara 1.436 .565 atau $1,36 \%$ dan menghantarkan 7 orang kadernya menjadi anggota legislatif di DPR RI.

Dari fakta diatas, maka dapat dikatakan bahwa Partai Keadilan telah memiliki basis masa dari aktivis dakwah tarbiyah. Seperti yang dikatakan oleh Presiden Partai Keadilan dalam Pidato Politiknya saat peresmian Dewan Pimpinan Wilayah Lampung bahwa Partai Keadilan adalah mata rantai dari gerakan dakwah tarbiyah yang dilakukan selama bertahun-tahun sebelum ini. ${ }^{23}$ Apalagi kemunculan Partai Keadilan ini setelah melalui proses yang panjang. Iaitu dengan melakukan survey kepada 6000 responden pada seluruh aktivis dakwah. Hasilnya $73 \%$ menginginkan untuk mendirikan partai politik, $27 \%$ menginginkan muncul sebagai organisasi masyarakat, dan sisanya memilih bertahan seperti semula. ${ }^{24}$

Partai Keadilan didirikan oleh para tokoh yang sama sekali tidak terkenal di masyarakat. Presiden Partai pertama adalah Dr. Nurmahmudi Ismail lulusan Universiti Texas merupakan seorang

22 “Dapat dilihat daripada kumpulan Pidato Politik Partai Keadilan yang dibacakan oleh Presiden Partai DR. Nur Mahmudi Ismail pada perasmian Dewan Pimpinan Wilayah dan Dewan Pimpinan Daerah sejak berdirinya pada ogos 1998 hingga Disember 1998. Kumpulan Pidato tersebut telah disusun dalam buku 'Sikap kami, Kumpulan Sikap Dakwah Politik PK \& PKS Periode 1998-2005'. Harakatuna Publishing. Bandung," .

${ }^{23}$ Sikap Kami, Kumpulan Sikap Dakwah Politik PK \& PKS Periode 19982005," Bandung: Harakatuna Publishing, (Bandung: Sekretariat Jendral DPP PKS Bidang Arsip dan Sejarah, 2007), 13.

${ }^{24}$ Ali Said Damanik, Ali Said Damanik (2002),op.cit, hlm.230, t.t. 


\section{Habibi : Partai Keadilan Sejahtera (PKS) Dalam Sorotan.........}

Doktor dan peneliti pada Badan Pengkajian dan Penerapan Teknologi BPPT dibawah kepemimpina BJ Habibie, Dr Hidayat Nur Wahid lulusan Universiti Islam Madinah sebagai Ketua Dewan Pendiri partai adalah seorang dosen Fakultas Pasca Sarjana Universiti Islam Negri Jakarta. Banyak tokoh yang meragukan keberadaan partai ini karena tidak mempunyai tokoh yang populer. Visi dari partai keadilan sejahtera yakni menjadi partai dakwah yang kokoh dalam berhikmad untuk umat bangsa dan negara. Sedangkan misi dari partai PKS yakni memperkokoh jati diri partai kader yang berkarakter bersih, peduli dan professional, Memperkokoh Good Party Governance melalui Sistem Manajemen Partai Dakwah (SMPD), Menjadikan PKS sebagai pelopor dalam pelayanan, pemberdayaan dan pembelaan rakyat, PKS menjadi kontributor peradaban.

Keistimewaan lainnya ialah partai ini dipimpin dan didukung oleh orang-orang yang terpelajar bahkan sangat terpelajar. Kebanyakan mereka adalah lulusan dari luar negeri dan memiliki hubungan dengan universiti-universiti lokal. ${ }^{25}$

\section{B. Priode Pemilu 1999 sampai Pemilu 2004}

Mengawali peran politiknya, PKS lebih mengedepankan politik moral. PKS sangat bersikap tegas pada permasalahan umat Islam. Sikap kepedulian PKS pertama kali ditunjukkan dengan memberikan pertolongan dan pembelaan kepada korban kerusuhan agama yang terjadi di Ambon Maluku pada tahun 1999. Bahkan secara tegas PKS juga mengeluarkan pernyataan resmi kepada pemerintah untuk menangkap semua yang menjadi dalang kerusuhan. $^{26}$

Selain itu PKS juga menaggapi isu-isu internasional, khususnya yang berkaitan dengan dunia Islam. Seperti isu ekspansi

${ }^{25}$ Prof Dr Nur Cholis Madjid, Prof Dr Nur Cholis Madjid (1999), "PK Nanti Muncul Sebagai Parti Penting", Dalam Tujuh Mesin Pendulang Suara, Yogyakarta:LKIS, p.192 (Yogyakarta: LKIS, 1999), p.192.

${ }^{26}$ Sikap Kami, op.cit, p. 44, t.t. 


\section{Habibi : Partai Keadilan Sejahtera (PKS) Dalam Sorotan.........}

Amerika ke Afghanistan dengan mendakwa Osamah bin Laden adalah pelaku dibalik serangan World Trade Centre di New York pada 11 september 2001. Selanjutnya adalah isu pendudukan tentera Israel keatas negara Palestin pada tahun 2001 dan pembunuhan terhadap masyarakat Palestin. Kedua isu besar tersebut disikapi dengan satu model penyikapan yang sama, iaitu dengan mengerahkan massanya dalam jumlah yang sangat besar untuk berdemonstrasi.

Dalam aksi demonstrasi Afghanistan PKS mengerahkan massanya lebih dari sepuluh rubu orang. ${ }^{27}$ sedangkan dalam menyikapi isu Palestin, massa yang berhasil dikumpulkan oleh PKS di Monas tanggal 7 april 2001 mencapai 95 ribu orang. ${ }^{28}$ Berikut ini adalah beberapa berita yang meliput aksi-aksi Partai Keadilan yang terjadi pada 7 april 2001. 1, Detik; Aksi untuk Palestin 1000 massa PKS Yogyakarta turun kejalan, mereka mengecam keras kebrutalan tentera Israel kepada warga Palestin. 2, Kompas; PKS mendirikan komite untuk pembebasan al-Aqsha yang diketuai oleh DR. Ahzami Samiun Jazuli. 3, Media Indonesia; Ribuan kader PKS menghadiri unjuk rasa besar-besaran di Monas. Acara itu bertajuk Perhimpunan agung solidaritas Partai Keadilan untuk kemanusiaan, tolak aksi kebrutalan Israel di Palestin. 4, Tempo Interaktif, PKS akan tetap mendukung perjuangan rakyat Palestin sampai Israel keluar dari semua wilayah Palestin. $^{29}$

Pengerahan massa ini adalah bukti yang menunjukkan kuatnya pengaruh massa partai, karena jumlah massa yang dikumpulkannya dalam setiap aksi-aksi demonstrasinya nampaknya selalu sama, selain jumlah yang besar, perilaku massa tersebut juga tertib dan santun. Demonstrasi itupun damai dan menarik. Dalam hal ini harian Media Indonesia pernah mengeluarkan editorial tentang perilaku kader PKS saat berdemonstrasi . ${ }^{30}$

\footnotetext{
27 "Kompas, October 20, 2001. P.10," t.t.

28 “Republika, April 8, 2001. P.3," t.t.

${ }^{29}$ Muqoddam Cholil, op.cit, p.308-309, t.t.

30 "Demonstrasi itu damai dan tertib, [accessed January 5, 2011], http://www.youtube.com/watch?v=ELU_owC85PM>," t.t.
} 
Menurut survei surat kabar jawa pos tanggal 3 september 2003, PKS adalah partai yang paling layak dipercaya dan bercitra baik dengan perolehan 31,4\% responden, PAN 17,3\%, PBB 9,6\%, Golkar $5,1 \%$, PPP 4,1\%, dan PKB serta PDI Perjuangan 3,5\%. Responden memilih PKS kerana kepeduliannya terhadap rakyat dan konstituennya, lalu anggota-anggotanya di DPR/DPRD tidak terlibat politik uang. Dari situ jelas, PKS berhasil mengumpulkan creadit point yang signifikan. Dan platform yang diterbitkan hanya sebuah konfirmasi bahwa mereka siap memimpin perubahan. ${ }^{31}$ Disini dapat disimpulkan bahwa peranan media saat itu dinilai telah membantu dalam menaikkan citra PKS ketengah-tengah masyarakat. Pengaruhnya sangat kuat dimasyarakat sehingga mampu menaikkan suara PKS pada pilihan raya 2004.

\section{Priode Pemilu 2004 sampai Pemilu 2009}

Politik moral mampu menaikkan suara PKS dari 1.436 .565 atau $1,36 \%$ pada pemilu 1999 meningkat menjadi 8.325.020 suara atau $7.34 \%^{32}$, satu pencapaian yang luar biasa dan berjaya menghantarkan presiden PKS DR. Hidayat Nur Wahid menjadi ketua MPR RI priode 2004-2009 dan menempatkan 45 kadernya di parlemen.

Konflik internal partai mulai terasa ketika para kadernya dari berbagai daerah seperti Solo dan Yogyakarta menanyakan sikap PKS dalam meyetujui kenaikan harga BBM. Seorang kader senior seperti Mashadi mantan anggota Malis Syuro PKS ikut angkat bicara, ia menyayangkan sikap PKS bertentangan dengan cita-cita awalnya menjadi partai yang melayani rakyat. Namun kenyataannya rakyat menjadi korban partai yang ingin bekerja sama dengan pemerintah. Mashadi mendesak agar PKS melalui Majlis Syuronya menarik dukungan dari pemerintah, hal ini didasari oleh kontrak politik yang

${ }^{31}$ Sapto Waluyo, Kebangkitan Politik Dakwah Konsep dan Praktik Politik Partai Keadilan Sejahtera di Masa Transis (Harakatuna Publishing, t.t.), p.207.

${ }^{32}$ Hasil Akhir Pemilu 2004, Komisi Pemiluhan Umum KPU tahun 2004, t.t. 


\section{Habibi : Partai Keadilan Sejahtera (PKS) Dalam Sorotan.........}

telah disepakati antara PKS dan Yudhoyono yang salah satu poin " Pemerintah tidak boleh menzalimi rakyat," dan menaikkan harga minyak lebih dari $180 \%$ adalah tindakan yang zalim. Mashadi melanjutkan bahwa jika PKS tidak menarik dukungannya terhadap pemerintah, maka konsekwensinya adalah 8 juta pemilih pada 2004 akan lari dari PKS kemudian yang paling penting adalah PKS telah gagal menjadi partai alternatif umat Islam.

Berita yang beredar dimasyarakat adalah PKS ikut menyetujui kenaikan harga BBM dalam rapat paripurna DPR yang membahas usulan RUU APBN yang baru, namun jika dilihat dari awal mula rapat pleno, PKS telah bersikap menolak kenaikan harga BBM tersebut dengan mengajukan opsi alternatif, namun opsi ini ditolak mentahmentah dalam rapat pleno.

Opsi yang dibahas dalam rapat pleno anggaran tersebut, yang pertama adalah tidak mengurangi subsidi Bahan Bakar Minyak (BBM) yang berjumlah Rp 113,7 trilliun. Konsekuensi dari opsi tersebut adalah bertambahnya defisit anggaran menjadi 1,4\% dan juga akan terdapat kekurangan anggaran (financial gap) sebesar Rp 23,2 trilliun. Akan tetapi, kalau ada subsidi sebesar itu, maka pemerintah tidak perlu menaikkan harga BBM.

Sedangkan opsi yang kedua adalah menurunkan subsidi BBM menjadi hanya Rp 89,2 trilliun. Konsekuensinya adalah terjadinya kenaikan harga BBM yang menambah beban rakyat. Keuntungannya, defisit anggaran bisa ditekan dibawah angka $1 \%$, atau tepatnya menjadi $0,9 \%$. Selain itu, pemilihan opsi tersebut bisa menghilangkan terjadinya kekurangan anggaran.

Sementara itu, Panitia Anggaran Fraksi PKS berpendapat bahwa 2 opsi tersebut masih mempunyai kelemahan sehingga mengusulkan opsi alternatif dari kedua opsi yang ditawarkan Panitia Kerja tersebut. Opsi yang ditawarkan oleh PKS hampir sama dengan opsi yang pertama, yaitu menolak pengurangan subsidi BBM

\footnotetext{
33 "Ini politik Bos, Tempo 33/XXXIV/10-16 october 2005, [accessed January 11, 2012] <http://majalah.tempointeraktif.com>,"
} 


\section{Habibi : Partai Keadilan Sejahtera (PKS) Dalam Sorotan.........}

(menolak kenaikan BBM). Akan tetapi ditambah dengan solusi realistis untuk menanggulangi kekurangan anggaran yang ada pada opsi pertama, yang menurut PKS bisa teratasi dengan tiga cara:

Pertama, memangkas 15\%-20\% sisa anggaran belanja kementerian atau lembaga yang belum terpakai terutama belanja modal dan belanja barang. Menurut Rama Pratama, Koordinator Kelompok Fraksi PKS di Panitia Anggaran, bahwa anggaran tersebut sampai bulan Agustus 2005 baru terpakai 30\% saja. Secara logika, sisa 4 bulan tidak mungkin akan memakai $70 \%$ anggaran yang belum terpakai. Dengan pemangkasan anggaran tersebut, maka akan menghemat anggaran negara sebesar kurang lebih Rp 15-20 trilliun.

Kedua, menghapus usulan Anggaran Belanja Tambahan (ABT) murni untuk kementerian / lembaga yang berjumlah $\mathrm{Rp} 3,1$ trilliun.

Ketiga, Meniadakan Anggaran Tambahan untuk Program Kompensasi Penurunan Subsidi (PKPS) BBM sebesar Rp 5 trilliun yang rencananya akan digunakan untuk pemberian subsidi langsung kepada orang miskin sebesar Rp 100.000 per orang.

Menurut Rama, pemerintah belum siap dengan Konsep Skema Program Kompensasi Pengurangan Subsidi (PKPS) BBM. Ia mengkhawatirkan akan terjadi penyimpangan dengan ketidaksiapan tersebut. Belum ada konsep "targeted subsidy" yang komprehensif dan integratif serta lemahnya mekanisme dan pengawasannya.

Sayangnya, usulan PKS tersebut di tolak oleh fraksi yang lain. Akhirnya rapat pleno menyepakati subsidi bahan bakar minyak (BBM) sebesar Rp 89,2 triliun, atau opsi kedua yang berdampak pada kenaikan harga BBM. Dan selanjutnya, hasil rapat pleno panitia anggaran yang berisi kenaikan BBM itu dibawa ke rapat paripurna DPR tanggal 27 September yang lalu. ${ }^{34}$

${ }^{34}$ Rama Pratama, Rama Pratama, "Kenaikan Harga BBM dan Posisi Fraksi PKS," dalam buku Dari Kader Untuk Bangsa Refleksi dan Wacana Perjuangan Kader-Kader PKS, DPP Partai Keadilan Sejahtera Sekertariat Jenderal Bidang Arsip dan Sejarah, Fitrah Rabban, Jakarta, p. 202-207 (Jakarta: Fitrah Rabban, t.t.). 


\section{Habibi : Partai Keadilan Sejahtera (PKS) Dalam Sorotan.........}

Inilah ujian pertama bagi PKS setelah memutuskan berkoalisi dalam pemerintahan Yudhoyono dan terpaksa menyetujui pengurangan subsidi BBM dan secara otomatis akan menaikan harga minyak. Meskipun PKS telah mengeluarkan berbagai alasan tentang sikapnya itu, tetap saja masyarakat menganggapnya sebuah pengkhianatan.

Ujian selanjutnya adalah isu iklan kontroversi yang dikeluarkan oleh PKS pada akhir 2008 menjelang pilihan raya 2009. Iklan ini di buat oleh Ipang Wahid putra Solahuddin Wahid yang menghabiskan dana Rp. 1 Billion. Berikut petikannya; 'Terima kasih guru bangsa! Terima kasih Pahlawan! Kami akan melanjutkan langkah bersama PKS demi Indonesia sejahtera". Iklan ini dibuat untuk menyambut hari pahlawan 10 November 2008. Kemudian untuk menggambarkan Guru Bangsa dan Pahlawan tersebut, iklan itu menampilkan 8 tokoh Nasional ( sesuai dengan Nombor PKS 8 ). Lalu munculah Soekarno, Soeharto, Hasyim Asy'ari, Ahmad Dahlan, M Natsir, M Hatta, Jendral Soedirman, dan Bung Tomo.

Kemunculan iklan ini banyak mendapat penentangan oleh berbagai kalangan, seperti Din Syamsudin ketua Muhammadiyah yang meminta agar iklan itu dicabut, karena penyantuman $\mathrm{KH}$ Ahmad Dahlan (pendiri Muhammadiyah) tidak ada izin dari pihaknya, apalagi iklan ini dikaitkan dengan politik yang bertujuan sesaat untuk menarik suara dari kalangan Muhammadiyah.

Penentangan itupun datang dari Sejarahwan Lembaga Ilmu Pengetahuan Indonesia (LIPI) Asvi Warman Adam, Ia mengatakan bahwa Soeharto bukan seorang pahlawan karena sampai saat ini Negara belum menetapkan ia sebagai seorang Pahlawan, dan kalau dia seorang guru bangsa, sebagai guru dalam bidang apa?. Iapun merasa heran dengan pencantuman Soeharto dalam iklan ini sehingga mempertanyakan Ideologi PKS. Menurutnya Soeharto bukanlah

35 "Din; Iklan PKS Lecehkan Muhammadiyah, [ accessed November 16, 2008], <http://nasional.inilah.com>.," t.t. 


\section{Habibi : Partai Keadilan Sejahtera (PKS) Dalam Sorotan.........}

pahlawan bangsa tetapi perusak bangsa karena telah meninggalkan hutang sebesar US\$ 150 Juta. $^{36}$

Penentangan selanjutnya datang dari Lukman Edy Sekretaris Jendral PKB, ia mengatakan "Akhir-akhir ini warga NU 'marah' pada PKS, karena Partai yang dipimpin oleh Tifatul Sembiring itu memasang gambar pandiri NU, KH Hasyim Asy'ari dalam iklan politiknya. Pada sisi lain PKS dikenal selalu menyerang amalan dan ajaran warga NU, tapi sekarang justeru memasang gambar pendiri NU untuk kepentingan politiknya.

Berbagai komentar dan kritikan pun datang dari pengamat dan lembaga penelitian, berikut adalah nama pengamat dan sedikit komentar mereka tentang iklan politik ini; Budiman Sujatmiko mantan aktivis PRD (mengecam PKS, Soeharto tidak layak jadi pahlawan), M Nur Soleh Kasubdit Nilai Kepahlawanan Perintisan dan Tanda Jasa (tidak melanggar peraturan), Agung Laksono Ketua umun Partai Golkar (menyambut baik iklan ini karena mengangkat Soeharto sebagai Pahlawan), Ari Sujito Pengamat Politik dari Universitas Gajah Mada (PKS mencoba mengambil suara Golkar), Mixil Mina aktivis Forum Kota Forkot (mengancam akan memboikot PKS pada pemilu 2009), Fachry Ali Pengamat Politik dan Ketua Komite Kebijakan Publik BUMN (PKS ingin menjadi parti terbuka dengan segmen pendukung yang lebih luas), Fahri Badoh Koordinator devisi korupsi politik Indonesia Corruption Watch ICW (PKS seakan mendukung penguasa orde baru), Amien Rais mantan ketua MPR (Iklan ini tidak perlu dibuat), Wiranto ketua umum Partai Hanura (Soeharto patut digelari pahlawan), Haryono Suyono mantan Menteri Kordinasi Kesejahteraan Rakyat (Iklan ini mencoba menampilkan sisi positif Soeharto), Rumadi peneliti The Wahid Institute (PKS ingin bebas dari stigma Wahabi), Yudi Latif direktur Eksekutif Reform Institute (iklan ini beresiko tinggi), Dedi Nur Hidayat Direktur pasca sarjana

36 "Sejarahwan, Soeharto bukan pahlawan dan guru bangsa, [accessed

November 10, 2008], <http://preview.detik.com>.," .

37 "PKB tutup pintu untuk PKS, [accessed November 11, 2008], <http://pemilu09.blogdetik.com>," 
Habibi : Partai Keadilan Sejahtera (PKS) Dalam Sorotan.........

Komunikasi Universitas Indonesia (PKS ingin menarik massa mengambang yang tidak tertampung), Ibnu Hamad Dosen Fakultas Komunikasi FISIP UI (PKS ingin menarik suara dari pendukung tokoh tersebut), Taufik Kiemas Ketua Dewan Penasehat Partai Demokrasi Indonesia Perjuangan PDIP (manyambut baik iklan ini), Lili Romli pengamat politik LIPI (iklan ini menandakan adanya keretakan di tubuh parti), Yusuf Warsyim Ketua Pemenangan Pemilu Partai Matahari Bangsa PMB (tidak menyukai iklan ini dan mencadangkan agar Ahmad Dahlan dipatenkan sebagai tokoh milik Muhammadiyah), Salahudin Wahid putra pendiri NU (menyambut baik iklan ini dan tidak melanggar hukum jika pendiri NU dimanfaatkan oleh PKS), Bambang Sulistomo putra Bung Tomo (menyambut baik gagasan ini), Sultan Hamengkubuwono X Gubernur DI Yogyakarta (iklan ini sah-sah saja dan tidak melanggar hukum), Effendi Ghazali pengamat komunikasi politik dari UI (memuji gagasan PKS).

Dari mulai ditayangkan iklan itu tanggal 9-10 dan 11 November 2008 ternyata efeknya dirasakan hingga tanggal 19 November 2008, saban hari media mengupdate komentar-komentar tokoh tentang iklan kontroversi ini. Diantara media cetak (surat kabar) yang memuat berita ini sejak tanggal 11-19 November 2008 adalah; Kompas, Republika, Tempo, Bisnis Indonesia, Seputar Indonesia, Rakyat Merdeka, Indopos. Sedangkan media internet adalah; www.detiknews.com, www.tempointeraktif.com, www.solopos.co.id, www.kompas.com, www.inilah.com, www.pemilu.okezone.com, www.mediaindonesia.com, dan www.antara.co.id.

Menurut Burhanuddin Muhtadi seorang analis politik charta politika, PKS terjebak dengan iklan yang dibuatnya, iklan PKS lebih mengedepankan faktor emosional daripada mempertimbangkan rasionalitas pemilih. Pilihan untuk mengangkat tokoh-tokoh seperti Soekarno, M. Natsir, KH Ahmad Dahlan, dan KH Hasyim Asy'ari

38 “R.B Suryaman M. Sastra, ' Heboh Iklan Soeharto,' [accessed January

12, 2012], <http://suryama.multiply.com>.," 
jelas menunjukkan tendensi politik PKS untuk memperbesar segmentasi konstituen PKS. PKS sadar bahwa target 20\% suara dalam Pemilu 2009 nanti akan sulit tercapai tanpa mengambil segmen pemilih partai lain. Pilihan untuk mencari suara dari partai lain itu sahsah saja, namun resikonya sangat besar. PKS langsung mendapatkan penolakan dari elit NU dan Muhammadiyah. ${ }^{39}$ Meskipun demikian, menurut Fachry Ali PKS merasa yakin bahwa citranya tidak akan turun disebabkan iklan ini, politik moral yang selama ini menjadi platform PKS telah dibuktikan sendiri dengan tidak adanya kader PKS di pejabat public dan parlimen yang terlibat korupsi sampai saat ini. ${ }^{40}$

Pro dan kontra diantara pengamat politik segera mendapat jawaban real dari hasil pilihan raya 2009, dimana PKS memperoleh suara sebanyak 8.206.955 suara atau 7,88\%, urutan ke empat, dibawah Partai Demokrat, Partai Golkar, dan PDI Perjuangan. Hasil ini jauh dari target yang dicanangkan $20 \%$. Jika dibandingkan dengan tahun 2004 yang memperolehi 8.325.020 suara atau 7.34\%. maka PKS mengalami penurunan suara 118.054 suara.

Darisini dapat disimpulkan bahwa peranan media dalam memberitakan PKS selama periode 2004-2009 telah berhasil menampilkan wajah lain dari parti ini. Terlepas apakah media berusaha menjelekkan citra PKS atau tidak, tapi selama ini pemberitaannya masih didasari oleh bukti dan kenyataan yang ada. Pada sisi lain media juga memberitakan prestasi parati ini, seperti partai paling bersih dari korupsi di antara partai lainnya, dan partai yang paling peduli dengan bencana. Hanya saja penulis menilai, pemberitaan semacam ini relatif tidak terlalu di ekspos oleh media berbanding berita-berita kontroversinya. Pada sisi lain, penulis menilai bahwa tingkat rasionalitas sebahagian masyarakat Indonesia masih emosional, sehingga prestasi dan citra baik PKS yang sudah dikenal

${ }^{39}$ Burhanuddin Muhtadi, "Kontroversi Iklan Politik" (Koran Seputar Indonesia, November 28, 2008, 2008).

40 "Pengamat:Pasang Soeharto di Iklan, PKS berjudi, [accessed November 11, 2008], < http://us.detiknews.com>," . 


\section{Habibi : Partai Keadilan Sejahtera (PKS) Dalam Sorotan.........}

oleh masyarakat mudah dilupakan disebabkan oleh adanya beritaberita yang kontroversi ini.

Menurut DR Teddy Surya Gunawan salah seorang kader PKS dan menjabat sebagai sekretasis Pusat Pelayanan Partai Keadilan Sejahtera Malaysia, suara yang hilang dari PKS diduga berasal dari suara mengambang (swing voter) yang masih melihat apa kata media, faktor lain yang menyebabkan menurunnya suara PKS adalah kenyataan yang tidak boleh dikesampingkan yaitu semua suara partai peserta pemilu 2004 mengalami penurunan yang drastis pada pemilu 2009 imbas dari ketokohan SBY dan Partai Demokrat, faktor lain adalah peran media yang mencoba menurunkan citra PKS dengan banyak meyoroti berita yang kontroversi tentang PKS. ${ }^{41}$

\section{PKS dalam menanggapi isu media tahun 2011.}

Pada tahun 2011, PKS juga mendapat berbagai pemberitaan yang tidak mengenakkan bagi pihaknya. Dimulai dari isu PKS menyelundupkan daging impor yang dimuat oleh majalah tempo edisi 14 maret - 20 maret 2011, kemudian isu pendiri PKS Yusuf Supendi menggugat petinggi PKS edisi 28 maret -3 april. Dilanjutkan dengan isu PKS dikait-kaitkan dengan gerakan Negara Islam Indonesia NII. Kali ini posisi media dapat dikatakan sebagai penyerang, bukan lagi sahabat bagi PKS. Pasalnya, berita media tidak lagi memuat prestasi PKS yang akan mengangkat citra partainya, justeru sebaliknya kali ini PKS bagai mendapat serangan yang merugikan pihaknya.

Dari gaya pemberitaan terhadap isu-isu tersebut, media terkesan tidak proporsional dengan data-data yang digunakannya tidak akurat, sumber berita hanya dari satu pihak dan tidak ada konfirmasi kebenaran dari pihak PKS. Model pemberitaan ini dapat dilihat dari kasus penyelundupan daging import yang dimuat dimajalah tempo, disitu dikatakan "Yayasan Pos Keadilan Peduli Umat (PKPU) kebanjiran jatah impor sebesar 9.759 ton. Lembaga ini didirikan pada 1999 oleh R.B. Suryama M. Sastra, politikus Partai Keadilan

${ }^{41}$ Wawancara penulis dengan DR Teddy Surya Gunawan, Kuala Lumpur January 14, 2012, . 


\section{Habibi : Partai Keadilan Sejahtera (PKS) Dalam Sorotan.........}

Sejahtera dan bekas anggota Dewan Perwakilan Rakyat (2004-2009). Pemegang kuota terbesar lainnya adalah CV Sumber Laut Perkasa, sebanyak 4.800 ton, dan PT Impexindo Pratama, 4.250 ton. Kedua perusahaan itu milik Basuki Hariman. Basuki boleh mendapatkan jatah karena merapat ke Suripto, anggota Majelis Syura PKS". ${ }^{2}$

Kedua pemberitaan diatas jelas tidak proporsional karena tidak mengajak pihak terlibat untuk dimintai konfirmasinya. Sehingga pihak PKPU dan Suripto terpaksa harus melayangkan surat keberatannya atas tuduhan tersebut, surat ini dimuat pada edisi majalah tempo edisi 21- 27 maret 2011. Dalam surat itu Suripto membantah bahwa tuduhan Basuki boleh mendapat jatah daging import sebab merapat ke Suripto adalah berita sangat tidak akurat dan tidak benar, Ia mengatakan bahwa dirinya tidak kenal dengan Basuki. Kemudian PKPU pun membantah tuduhan yayasannya mendapat jatah 9.759 ton, yang benar adalah $9.759 \mathrm{~kg}$. menurutnya bahwa daging itu adalah daging domba beku dari komunitas muslim Australia untuk Hari Raya Qurban. Daging inipun bukan untuk keperluan bisnis, tapi untuk dibagikan kepada masyarakat miskin yang memerlukan. ${ }^{43}$

Isu lain yang lebih panas adalah munculnya Yusuf Supendi mantan pendiri PKS yang membuka aib sekaligus menggugat petinggi PKS dengan berbagai tuduhan, diantara tuduhannya adalah penggelapan dana kampanye Adang Darojatun dalam Pemilihan Gubernur Jakarta, pemilu tahun 1999 PKS mendapat dana 94\% berasal dari Timur Tengah, Petinggi PKS melakukan poligami dengan tidak adanya wali nikah, PKS adalah neo NII, dan pemecatan dirinya dari keanggotaan partai yang ia nilai tidak prosuderal. Kasus ini langsung mendapat sorotan media di tanah air. Diantara media yang memberitakan kes ini adalah majalah tempo dan dijadikan sebagai liputan khusus edisi 28 maret - 3 april 2011 "Anis Matta (sekretasis jendral PKS) menggelapkan dana kempanye Adang Rp. 10 Miliyar

42 "Majalah Tempo march 14, 2011, [accessed January 14, 2012], $<$ http://majalah.tempointeraktif.com $>$,".

43 "Majalah Tempo 27 March 2011, p. 6-8.,. 


\section{Habibi : Partai Keadilan Sejahtera (PKS) Dalam Sorotan.........}

dari total Rp. 40 Miliyar", “Anis Matta mendapatkan dana Rp. 34 Miliyar dari Wiranto (salah seorang calon president 2004) agar PKS mendukungnya", Kompas pun meliput berita ini dari tanggal 23 maret - 29 maret 2011 antaranya adalah "Yusuf Supendi melaporkan President PKS Luthfi Hasan Ishak ke Polis dan Badan Kehormatan DPR kerana kerap mengirimkan SMS bernada ancaman."44 Eramuslim.com "Yusuf Supendi: PKS mendapat dana dari Yusuf Kalla sebesar Rp. 34 Milliar untuk dana kampanye President 2004", 45 Detik.com “ Yusuf Supendi melaporkan PKS ke Komisi Pemberantasan Korupsi KPK", 46

Menurut para petinggi PKS, bahwa munculnya isu akhir-akhir ini yang memburukkan citra PKS adalah sebuah sekenario besar untuk menjegal PKS pada pemilu 2014. Hal ini diungkapkan oleh Tifatul Sembiring, Anis Matta dan Fahri Hamzah. Isu itu sebenarnya bermula dari munculnya video seks mirip Anis Matta yang beredar di internet, kemudian disusul oleh Isu penyelundupan daging impor, kemudian muncul statemen Yusuf Supendi yang secara tiba-tiba membeberkan skandal petinggi PKS dengan bukti-bukti yang ia punya. Meskipun demikian, PKS mempersilahkan Yusuf untuk melaporkan datadatanya itu kepada pihak yang berwenag dan PKS tidak akan melawan balik serangan Yusuf demi menjaga kehormatan orang yang dulu pernah menjadi pengasas partai dakwah ini. ${ }^{47}$ Semua tuduhan Yusuf terhadap PKS dan petingginya yang dilaporkan ke Polis, KPK, Badan Kehormatan DPR sampai saat ini tidak mendapatkan respon apa-apa dari penegak hukum. Ini membuktikan lemahnya tuduhan itu.

\footnotetext{
44 "Yusuf Supendi laporkan luthfi ke polis, [accessed January 17, 2012], $<$ http://nasional.kompas.com>,"

45 “PKS akhirnya dibuka yusuf supendi, [accessed January 17,2012], <http://www.eramuslim.com," t.t.

46 "Yusuf Supendi laporkan PKS ke KPK, [accessed January 17, 2012], $<$ http://us.foto.detik.com>,".

47 "Lihat majalah tempo wawancara dengan Anis Matta, April 3, 2011, p $15, "$
} 


\section{Habibi : Partai Keadilan Sejahtera (PKS) Dalam Sorotan.........}

Menurut DR Teddy, media di Indonesia belum sepenuhnya murni pemberitaannya, munculnya berita, wawancara dan pengamat politik di station TV atau di majalah bukanlah gratis tanpa biaya, tapi tergantung siapa yang mampu membayar media. Meskipun demikian, strategi yang sekarang digunakan oleh PKS saat ini dalam menghadapi perang media adalah memiliki media sendiri. Kader PKS pun diminta agar aktif mengirimkan tulisannya ke media, termasuklan aktif di jejaring sosial seperti facebook dan twitter untuk menyebarkan gagasan kepada masyarakat dan ikut membantah fitnah-fitnah yang dilakukan media. ${ }^{48}$

\section{Kesimpulan}

Perjalanan PKS dari mulai didirikan hingga sekarang menarik perhatian untuk dikaji. Pasalnya, partai Islam yang lahir dari rahim reformasi ini sampai sekarang masih konsisten dengan agendanya membentuk good government. Kiprah politiknya yang elegan dan santun menjadi ciri khas tersendiri, didukung oleh kader yang militan dan solid menjadikan partai ini tidak mudah digoyahkan oleh perpecahan internal ataupun serangan dari lawan-lawan politiknya. Pilihan raya 2009 menempatkan partai ini pada posisi ke empat diatas semua partai-partai Islam. Sehingga kehadirannya menjadi sorotan pengamat dan media massa "apakah PKS akan menjadi alternative kekuatan Islam di Indonesia".

Dalam kajian ini penulis menilai bahwa diawal-awal kemunculan PKS, media banyak meliput aksi-aksi sosial PKS dan berhasil mengangkat citra partai ini, terbukti dengan meningkatnya suara pemilih hingga $600 \%$ pada pilihan raya 2004. Pada periode berikutnya, media banyak memuat sisi lain dari PKS, berita kenaikan harga BBM tahun 2005 dibesar-besarkan oleh media yang seakanakan PKS menyetujui kenaikan itu, pada sisi lain tidak banyak media yang memuat klarifikasi dan bantahan dari pihak PKS. Begitu pula dalam kasus iklan kontroversi, media lebih banyak menampilkan

48 "Wawancara penulis dengan DR Teddy Surya Gunawan, Kuala Lumpur, January 14, 2012,". 
Habibi : Partai Keadilan Sejahtera (PKS) Dalam Sorotan.........

pendapat yang kontra daripada suara-suara yang netral. Peran media ini setidaknya telah berhasil menghalagi pemilih baru bagi PKS, target $20 \%$ jauh dari kenyataan. Akan tetapi PKS boleh dikatakan berjaya pada pilihan raya 2009 karena mampu bertahan dengan suaranya yang hilang hanya 118.054 suara saja berbanding dengan partai lainnya yang turun drastis. Pada periode berikutnya, media semakin memperlihatkan loyalistasnya kepada pihak tertentu, hal ini ditandai dengan munculnya sederetan fitnah terhadap PKS yang dihebohkan oleh media dengan tujuan untuk menjegal PKS pada piliha raya 2014. Kes ini semakin menguatkan bahwa media akan mengikut kehendak majikan yang berani membayar mahal. Dari data ini, perlu adanya strategi khusus yang harus dimiliki oleh PKS untuk merespon sikap media agar pengalaman pada pemilu 2009 tidak terulang lagi pada pemilu 2019. 
Habibi : Partai Keadilan Sejahtera (PKS) Dalam Sorotan.........

\section{Daftar Pustaka}

Abuza, Zachary. "Political Islam and Violence in Indonesia," Routledge Taylor \& Francis Group

Aminah, Siti. "Politik Media, Demokrasi dan Media Politik," [accessed January 3, 2012], 〈http://journal.unair.ac.id〉.

Bunte, Marco and Andreas Ufen, "Democratization in Post-Suharto Indonesia," Routledge Contemporary Southeast Asia Series

Budhiardho Miriam, Demokrasi, Jakarta: Gramedia, 2008.

Castle, Lance, Tujuh Mesin Pendulang Suara, Yogyakarta: LKIS, 1999.

Cholil, Muqoddam, Sejarah Perkembangan Partai-Partai Islam diIndonesia Mulai Zaman Orde Baru Sehingga Tahun 2001, Jabatan Sejarah dan Tamadun Islam Akademi Pengajian Islam Universiti Malaya Kuala Lumpur, 2009.

Damanik, Ali Said, Fenomena Partai Keadilan, Jakarta: Teraju, 2002.

Demonstrasi itu damai dan tertib, [accessed January 5, 2011], http://www.youtube.com/watch?v=ELU_owC85PM>,

Din, Syamsyuddin; Iklan PKS Lecehkan Muhammadiyah, [ accessed November 16, 2008], <http://nasional.inilah.com 
Freedomhouse, "Combined Average Ratings: Independent Countries in 2009," [accessed September 26, 2009], $<$ http://www.freedomhouse.org>; "Polity IV Country Report 2007, "Indonesia,"[accessedseptember26,2009], ://www.systemicpeace.org/polity/Indonesia2007.pdf>.

Jawa Timur: Tembok Pembatas Mulai Terbelah“, Kompas June 22, 2009

Hidayat Nurwahid Manolak Fasilitas Mobil Volvo, [accessed on october 10, 2004] <http://berita.liputan6.com>.

Ini politik Bos, Tempo 33/XXXIV/10-16 october 2005, [accessed January 11,2012$]<$ http://majalah.tempointeraktif.com>.

Madjid, Nur Cholis (1999), "PK Nanti Muncul Sebagai Parti Penting”, Dalam Tujuh Mesin Pendulang Suara, Yogyakarta:LKIS,

Mujani, Saiful and William Liddle, 2004. "Politics, Islam and Public Opinion”, Journal of Democracy, Vol. 15, NO.1, January 2004.

Mujani, Saiful and William Liddle, 2009.“ Muslim Indonesia's Secular Democracy," Asian Survey Vol. XLIX. NO.4. July/August 2009

M.Jasin: "Banyak Pejabat Negara Indonesia Terlibat Kasus Korupsi," [accessed January 3, 2012], <http://www.suarapembaruan.com>.

Muhtadi, Burhanuddin, "Kontroversi Iklan Politik," Koran Seputar Indonesia, November 28, 2008

Pratama, Rama "Kenaikan Harga BBM dan Posisi Fraksi PKS," dalam buku Dari Kader Untuk Bangsa Refleksi dan Wacana Perjuangan Kader-Kader PKS, DPP Partai Keadilan Sejahtera 
Sekertariat Jenderal Bidang Arsip dan Sejarah, Fitrah Rabban, Jakarta

"Partai-Partai Politik Indonesia: Ideologi, Strategi, dan Program," Litbang Kompas 1999

R.B Suryaman M. Sastra, “ Heboh Iklan Soeharto,” [accessed January 12, 2012], <http://suryama.multiply.com>.

Salim, Arsekal, "Partai Islam dan Relasi Agama-Negara, "Pusat Penelitian IAIN Jakarta 1999

Sekretariat Jendral DPP PKS Bidang Arsip dan Sejarah ( 2007), "Sikap Kami, Kumpulan Sikap Dakwah Politik PK \& PKS Periode 1998-2005,” Bandung: Harakatuna Publishing,

Sejarahwan, Soeharto bukan pahlawan dan guru bangsa, [accessed November 10, 2008], 〈http://preview.detik.com>.

Yusuf Supendi laporkan luthfi ke polis, [accessed January 17, 2012], $<$ http://nasional.kompas.com

Yusuf Supendi laporkan PKS ke KPK, [accessed January 17, 2012], <http://us.foto.detik.com>,

Waluyo, Sapto “ Kebangkitan Politik Dakwah Konsep dan Praktik Politik Partai Keadilan Sejahtera di Masa Transisi," Harakatuna Publishing 